\title{
Efektivitas Model Pembelajaran Problem Solving dan Discovery Learning Terhadap Kemampuan Berpikir Kritis Siswa Sekolah Dasar
}

\author{
Maulid Anwar Sidiq ${ }^{1}$, Tego Prasetyo ${ }^{2}$ \\ Program Studi Pendidikan Guru Sekolah Dasar,Universitas Kristen Satya Wacana \\ E-mail 292016137@ student.uks.edu ${ }^{1,} \underline{\text { Prasetyotego@ Gmail.com }}^{2}$
}

\begin{abstract}
Abstrak
Penelitian menggunakan jenis penelitian eksperimen semu. Desain penelitian menggunakan Nonequivalent Control Group Design. Penelitian ini bertujuan untuk mengetahui efektifitas model Problem solving, dan Discovery Learning terhadap kemampuan berpikir kritis siswa kelas 5 SD dalam pelajaran Matematika. Teknik pengumpulan dalam penelitian ini berupa observasi dan tes. Observasi didapatkan dengan presentase keterlaksanaan data berupa tahapan-tahapan implementasi model pembelajaran, sedangkan teknik tes berupa tes awal (Pretest) dan tes akhir (Posttest) dalam bentuk tes uraian. Teknik analisis data berupa Deskriptif kuantitatif yang digunakan untuk uji prasyarat, dan Uji Annova, agar dapat mengetahui perbedaan rata-rata antara yang menggunakan model kontrol, Problem Solving, dan Discovery Learning. Hasil uji Annova memperoleh nilai signifikan $0,015<0,05$, sehingga $\mathrm{H}_{0}$ ditolak, yang berarti berdapat perbedaan antara yang menggunakan model kontrol dan eksperimen. Hal ini dapat dilihat dari hasil rata-rata pretest dan posttest pembelajaran konvensional 61,19 dan 69,47. Rata-rata nila pretest dan posttest pada kelompok eksperimen yang menggunakan model Problem Solving yaitu 60,36 dan Posttest 75,6, dan nilai rata-rata postest model Discovery Leraning yaitu 60,92 dan Posttest 70,43. Hal ini dapat diambil kesimpulan bahwa model Problem Solving lebih efektif dibandingkan dengan model Discovery Learning.
\end{abstract}

Kata Kunci: Konvensional, Problem Solving, Discovery Learning, dan Kemampuan Berpikir Kritis

\begin{abstract}
The type of this research used appearance experimental. The design used nonequalivalent control group design. The purpose of this research to know about effectiveness problem solving and discovery learning model to critical thinking skills of grade 5 students in mathematics learning. Data collectiob techniques using observat56n and tests. Obsevasi was obtained with the precentage of data implementation in the form of stage of the learning model implementation, while the test techniques was in the form of an (pretest) and final test (posttest) in the form of description test. Data analysis used was quantitative description us a prerequisite, ANNOVA test to know abaut differences of average between control model, Problem Solving and Discovery Learning. The result of Anova test aboined a significant value of $0,015<0,05$, then $\mathrm{H}_{0}$ is rejected with mean dear were differences between control model and eksperiment. It's proven by avarage pretest and posttest result of convensional learning 61,9 and 69,47. Result avarage pretest and posttest in experimental group using the problem solving model were 60,36 and posttest 75,6 and the result average posttest model disacovery learning were 60,92 and posttest 70,43 . This showed that Problem Solving model is more effechive than Discovery Learning model.
\end{abstract}

Keywords: Conventional, Problem Solving, Discovery Learning, and Critical Thinking Skills

@ Jurnal Basicedu 2020

$\triangle$ Corresponding author :

Address : Klumpit RT 04/01, Salatiga

Email :292016137@student.uksw.edu

ISSN 2580-3735 (Media Cetak)

Phone ISSN 2580-1147 (Media Online) 


\section{PENDAHULUAN}

Kurikulum yang sekarang berlaku di Indonesia yaitu kurikulum 2013, prinsip dasar kurikulum 2013 adalah pemusatan keahlian guru dalam menerapkan proses pembelajaran yang bersifat faktual, menantang dan mempunyai makna bagi peserta didik sesuai yang tertuang dalam tujuan pendidikan nasional (Kurniawan, 2017: 390). Tujuan dari kurikulum 2013 yaitu agar manusia Indonesia mampu mempunyai pribadi yang beriman, produktif, afektif, inovatif, dan kreatif serta dapat berpartisipasi dalam kehidupan masyarakat, berbangsa, negara, dan dunia (Permendikbud No 69 Tahun 2013 Tentang Kerangka Dasar dan Struktur Kurikulum Sekolah Menengah Atas/Madrasah Aliyah). Kurikulum 2013 terdapat pembelajaran yang bersifat tematik.

Pembelajaran tematik mencakup beberapa mata pelajaran untuk memberikan pengalaman yang bermakna kepada peserta didik. Pada model pembelajaran tematik peserta didik terlibat aktif baik secara individu maupun kelompok. Peserta didik belajar berdasarkan pengalaman, kebutuhan, dan perkembangan peserta didik (Rusman, 2012:254). Hal ini sejalan dengan hakikat pembelajaran tematik terpadu menurut (Permendikbud No.22 Tahun 2016 Tentang Standar Proses Pendidikan Dasar dan Menengah) pembelajaran yang menggabungkan beberapa mata pelajaran menjadi sub tema.

Pembelajaran tematik cocok diterapkan pada pendidikan jenjang sekolah dasar, karena melibatkan peserta didik secara aktif agar memperoleh pengalaman secara langsung, menumbuhkan kreativitas peserta didik untuk dapat menemukan pengetahuan secara mandiri. Dilihat dari sisi yang lain, pembelajaran tematik cocok diterapkan pada pendidikan jenjang sekolah dasar karena dapat menggabungkan beberapa kompetensi dasar, indikator, dan muatan pembelajaran yang berpengaruh terhadap penghematan waktu. Materi pembelajaran mempunyai fungsi sebagai sarana atau alat pembelajaran. Tidak hanya itu dalam pembelajaran tematik peserta didik mendapatkan materi pembelajaran yang lengkap dan sesuai prosesnya, sehingga peserta didik dapat menguasai materi dan dapat diterapkan dalam kehidupan sehari-hari (Rusman, 2012:258)

Materi pembelajaran matematika yang dilaksanakan secara terpisah dengan materi pembelajaran yang lain. Hal ini dapat terjadi karena adanya perbedaan karakteristik objek kajian matematika dengan pembelajaran yang lain. Materi matematika yang terdapat pada buku guru hanya berupa sedikit teori, sehingga dalam pembelajaran harus menggunakan sumber lain untuk menambahkan pengetahuan tentang materi pembelajaran. Dengan pembelajaran matematika manusia dapat menumbuhkan kemampuan berpikir, sehingga dapat menjadi dasar ilmu untuk perkembangan teknologi dimasa yang akan datang. Konsep matematika harus ditanamkan dengan benar pada peserta didik sekolah dasar. Perkembangan matematika dalam bidang teori bilangan belajar, peluang, analisis, dan matematika distrik menjadi landasan bagi perkembangan informasi teknologi dan komunikasi (Maarif \& Wahyudi, 2015). Hasil belajar pembelajaran matematika yaitu membentuk sikap siswa yang logis, dapat berpikir kritis, kreatif, disiplin, dan cermat (Sumianto,52: 2018)

Penelitian Trends in International Mathematics and Science Study 2015 (Azizah dkk, 2018: 62) menjelaskan bahwa Indonesia menduduki peringkat ke 45 dari 50 negara pada pelajaran matematika. Hasil pengamatan juga dilakukan 
pada saat proses pembelajaran matematika di sekolah

dasar yang akan dijadikan penelitian didapatkan masalah, yaitu pada saat proses pembelajaran berlangsung peserta didik belum sepenuhnya memahami materi yang diajarkan guru dan ketika guru mengajukan pertanyaan peserta didik hanya diam saja, beberapa peserta didik yang masih kebingungan untuk memecahkan soal matematika yang disampaikan guru, beberapa peserta didik yang sungkan untuk bertanya kepada guru jika masih belum memahami materi, penggunaaan model pembelajaran konvesional maupun example non example membuat peserta didik belum sepenuhnya antusias untuk mengikuti pembelajaran dan memahami materi. Dari beberapa masalah yang didapatkan guru harus mengembangkan kamampuan peserta didik dalam pembelajaran. Kemampuan peserta didik yang dikembangkan yaitu kemampuan berpikir kritis.

Hakikat dari berpikir kritis menurut Johnson (Yaumi, 2012:67) yaitu suatu proses yang tersusun yang dapat digunakan peserta didik untuk mengevaluasi fakta, asumsi, logika, dan bahasa yang mendasari pernyataan orang lain. Berdasarkan asumsi tersebut guru bisa menggunakan model pembelajaran untuk mengembangkan kemampuan berpikir kritis.

Salah satu model pembelajaran yang dapat digunakan guru untuk menumbuhkan kemampuan berpikir kritis peserta didik yaitu model Problem Solving. Tujuan dari penggunaan model Problem Solving yaitu peserta didik mampu memahami masalah sesuai dengan kaidah ilmiah dan langkahlangkah berpikir kritis (Suyanto \& Jihad, 2013: 124). Tidak hanya model pembelajaran Problem Solving, tetapi model Discovery Learning juga dapat berpengaruh terhadap kemampuan berpikir kritis peserta didik. Model Discovery Learning menuntut peserta didik agar dapat mencari pengetahuan yang berhubungan dengan materi pembelajaran secara mandiri dengan melakukan penemuan konsep yang sebelumnya belum diketahui (Darmadi, 2017: 108).

Model Problem Solving dan Discovery Learning mempunyai perbedaan yang terdapat pada prinsip belajar. Pada model Problem solving mempunyai prinsip belajar yang memberikan tekanan kepada peserta didik agar dapat menyelesaikan masalah. Hal ini berbeda dengan prinsip belajar model Discovery learning yaitu menekankan pada penemuanpenemuan tentang konsep yang belum diketahui sebelumnya, sehingga guru tidak memberikan materi pembelajaran secara final (Darmadi, 2017: 107-108).

Penelitian Sisnanto (2019) yang berjudul "Efektivitas Model Pembelajaran Problem Solving Dan Group Investigation Terhadap Peningkatan Kemampuan Berpikir Kritis Peserta didik Kelas 4 SD Dalam Pelajaran Matematika". Model pembelajaran Problem Solving berpengaruh terhadap berpikir kritis. Hal ini dapat dilihat dari dari rata-rata skor keterampilan berpikir kritis peserta didik menggunakan Problem Solving 87,52 dan ratarata yang menggunakan model Group Investigation yaitu 81,97.

Penelitian Meidinda (2018) yang berjudul "Pengaruh Model Pembelajaran Discovery Learning Terhadap Kemampuan Berpikir Kritis Matematis Peserta didik Kelas VIII". Model pembelajaran Discovery Learning berpengaruh terhadap kemampuan berpikir kritis. Hal ini dapat dilihat dari pencapaian ketuntasan dalam pembelajaran matematika yang mengikuti pembelajaran dengan kelas eksperimen model Discovery Learning adalah 25,743. Akan tetapi, 
rata-rata skor keterampilan berpikir kritis peserta didik dalam pembelajaran matematika yang mengikuti pembelajaran dengan pembelajaran kelas kontrol adalah 24,257. Berdasarkan hasil pencapaian ketuntasan dapat disimpulkan bahwa penggunaan model Discovery Learning kemampuan berpikir kritis peserta didik lebih tinggi daripada kemampuan berpikir kritis peserta didik yang tidak menggunakan model Discovery Learning.

Berdasarkan latar belakang penelitian tersebut untuk menghilangkan keraguan terhadap keefektifan model pembelajaran Problem Solving dan Discovery Learning terhadap kemampuan berpikir kritis dillakukan penelitian dengan mengambil judul "Efektivitas Model Pembelajaran Problem Solving Dan Discovery Learning Terhadap Kemampuan Berpikir Kritis Siswa Kelas 5 SD dalam Pelajaran Matematika”.

\section{METODE}

Jenis penelitian yang digunakan oleh peneliti adalah jenis penelitian eksperimen. Kelompok yang terdapat pada penelitian eksperimen semu yaitu kelompok kontrol dan kelompok eksperimen. Kelompok eksperimen merupakan kelompok yang digunakan pada penelitian ini yaitu dengan menggunakan model pembelajaran Problem Solving dan Discovery Learning, sedangkan kelompok kontrol merupakan kelompok yang digunakan pada pembelajaran konvensional. Hal ini sama dengan subjek penelitian, karena pada subjek penelitian terbagi menjadi 2 kelompok yaitu kelompok kontrol dan eksperimen.

Populasi penelitian ini dilaksanakan di gugus Gajah Mada Kota Salatiga. Sekolah Dasar yang berada diwilayah gugus Gajah Mada, yaitu (1) SDN Kecandran 01, (2) SDN Dukuh 01, (3) SDN Dukuh 02, (4) SDN Dukuh 03, dan (5) SDN
Dukuh 05. Sampel pada penelitian ini SDN Dukuh 02 sebagai kelompok eksperimen 1, SDN Dukuh 01 sebagai kelompok eksperimen 2 dan SDN Kecandran 01 sebagai kelompok kontrol.

Tabel 1. Desain penelitian Nonequivalent Control Group Design (Sugiyono, 2012:116)

\begin{tabular}{|l|l|l|l|}
\hline $\mathrm{G}_{1}$ & $\mathrm{O}_{1}$ & $\mathrm{X}_{1}$ & $\mathrm{O}_{2}$ \\
\hline $\mathrm{G}_{2}$ & $\mathrm{O}_{3}$ & $\mathrm{X}_{2}$ & $0_{4}$ \\
\hline
\end{tabular}

\section{Keterangan:}

$\mathrm{G}_{1}=$ Kelompok eksperimen pertama

$\mathrm{G}_{1}=$ Kelompok eksperimen kedua

$\mathrm{O}_{1}=$ Hasil pretest eksperimen pertama

$\mathrm{O}_{2}=$ Hasil posttest eksperimen pertama

$\mathrm{X}_{2}=$ model satu model pembelajaran Problem Solving

$\mathrm{X}_{2}=$ model dua model pembelajaran Discovery Learning

$\mathrm{O}_{3}=$ Hasil pretest eksperimen kedua

$\mathrm{O}_{4}=$ Hasil posttest eksperimen kedua

\section{HASIL DAN PEMBAHASAN}

Teknik pengumpulan data yang dijadikan tolak ukur ada dua yaitu tahapan proses pembelajaran dan hasil kemampuan berpikir kritis. Tahapan proses pembelajaran yang digunakan observasi dan hasil kemampuan berpikir kritis menggunakan teknik tes. Pengertian teknik tes, yaitu teknik pengumpulan data yang menggunakan pertanyaan yang harus dijawab oleh siswa. (Arifin, 2011: 226). Hal ini berbeda dengan teknik observasi, yaitu suatu tahapan yang kompleks dan tersusun dari proses psikologis dan biologis dalam prsoses engamatan maupun proses ingatan. Observasi yang dilaksanakan peneliti melakukan pengamatan secara langsung untuk mendapatkan data di lokasi penelitian Hadi (dalam Sugiyono, 2012: 203)

Tabel 2. Descriptive Statistics Kontrol

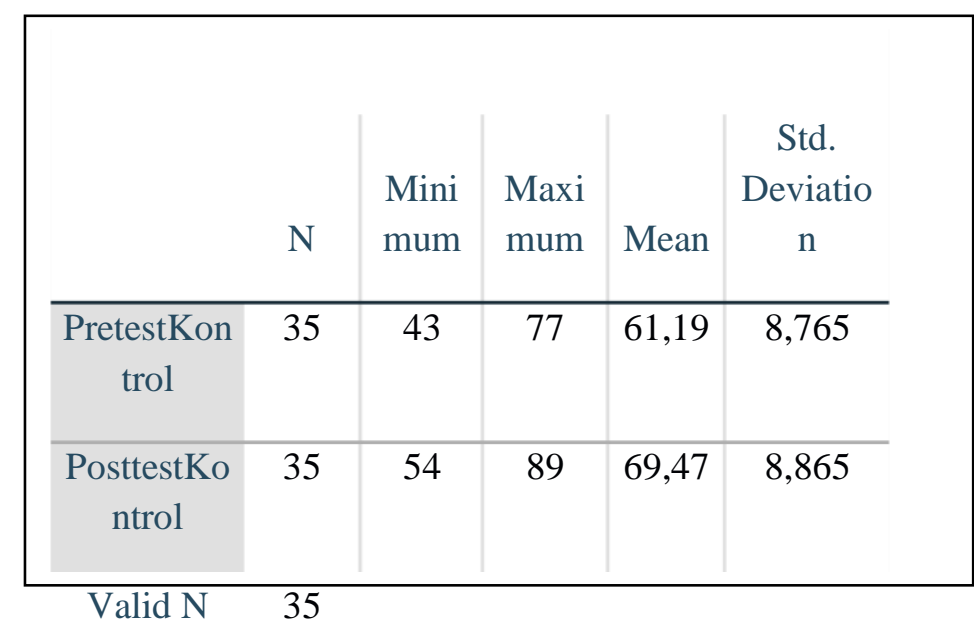


Berdasarkan tabel di atas, maka dapat diketahui nilai dan rata-rata Pretest dan Posttest kelompok kontrol mempunyai perbedaan. Nilai terendah pada nilai Pretest 43 dan nilai Posttest 54. Nilai tertinggi pada Pretest 77 dan Posttest 89. Rata- rata nilai Pretest 61,19 dan Posttest 69,47

\section{Tabel 3. Descriptive Statistics Problem Solving}

\begin{tabular}{|c|c|c|c|c|c|}
\hline & $\mathrm{N}$ & $\begin{array}{c}\text { Mini } \\
\text { mu } \\
\mathrm{m}\end{array}$ & $\begin{array}{c}\text { Max } \\
\text { imu } \\
\text { m }\end{array}$ & $\begin{array}{c}\text { Mea } \\
\mathrm{n}\end{array}$ & $\begin{array}{c}\text { Std. } \\
\text { Deviati } \\
\text { on }\end{array}$ \\
\hline $\begin{array}{l}\text { PretestP } \\
\mathrm{S}\end{array}$ & 32 & 44 & 80 & $\begin{array}{r}60,3 \\
6\end{array}$ & 8,694 \\
\hline $\begin{array}{l}\text { PosttestP } \\
\text { S }\end{array}$ & 32 & 58 & 93 & $\begin{array}{r}75,6 \\
1\end{array}$ & 8,806 \\
\hline $\begin{array}{l}\text { Valid N } \\
\text { (listwise } \\
\text { ) }\end{array}$ & 32 & & & & \\
\hline
\end{tabular}

Berdasarkan tabel di atas, maka dapat diketahui nilai dan rata-rata Pretest dan Posttest kelompok eksperimen Problem Solving mempunyai perbedaan. Nilai terendah pada nilai Pretest 44 dan nilai Posttest 58. Nilai tertinggi pada Pretest 80 dan Posttest 93. Rata- rata nilai Pretest 60,36 dan Posttest 75,6.

Tabel 4. Descriptive Statistics Discovery Learning

\begin{tabular}{lc|r|r|r|r} 
& & $\begin{array}{c}\text { Mini } \\
\text { mu } \\
\text { m }\end{array}$ & $\begin{array}{c}\text { Max } \\
\text { imu } \\
\mathrm{m}\end{array}$ & $\begin{array}{c}\text { Mea } \\
\mathrm{n}\end{array}$ & $\begin{array}{c}\text { Std. } \\
\text { Deviati } \\
\text { on }\end{array}$ \\
\hline $\begin{array}{l}\text { PretestD } \\
\text { L }\end{array}$ & 29 & 42 & 71 & $\begin{array}{r}60,9 \\
2\end{array}$ & 6,773 \\
\hline $\begin{array}{l}\text { Posttest } \\
\text { DL }\end{array}$ & 29 & 54 & 89 & 70,4 & 9,337 \\
\hline $\begin{array}{l}\text { Valid N } \\
\text { (listwise }\end{array}$ & 29 & & & & \\
\hline
\end{tabular}

Berdasarkan tabel di atas, maka dapat diketahui nilai dan rata-rata Pretest dan Posttest kelompok eksperimen Discovery Learning mempunyai perbedaan. Nilai terendah pada nilai Pretest 42 dan nilai Posttest 54. Nilai tertinggi pada Pretest 71 dan Posttest 89. Rata- rata nilai Pretest 60,92 dan Posttest 70,43

\section{Tabel 5. Hasil Pengukuran Kemampuan} Berpikir Kritis

\begin{tabular}{|l|l|l|l|}
\hline $\begin{array}{c}\text { Pengukur } \\
\text { an }\end{array}$ & \multicolumn{2}{|c|}{ Rata-rata (Mean) } & Selisih \\
\hline & $\begin{array}{c}\text { Eksperimen } \\
1\end{array}$ & Kontrol & \\
\hline Pretest & 60,36 & 61,19 & 0,83 \\
\hline Posttest & 75,61 & 69,47 & 6,14 \\
\hline
\end{tabular}

Selisih pretest dan posttest kelas eksperimen 1 yang menggunakan model Problem Solving dengan kelompok kontrol yaitu 0,83 dan 6,14.

\section{Tabel 6. Hasil Pengukuran Kemampuan} Berpikir Kritis

\begin{tabular}{|c|c|c|c|}
\hline \multirow{3}{*}{$\begin{array}{c}\text { Penguk } \\
\text { uran }\end{array}$} & \multicolumn{2}{|c|}{ Rata-rata (Mean) } & \multirow[t]{2}{*}{ Selisil } \\
\hline & Eksperimen & Kontrol & \\
\hline & 2 & & \\
\hline Pretest & 60,92 & 61,19 & 0,27 \\
\hline Posttest & 70,43 & 69,47 & 0,96 \\
\hline
\end{tabular}

Selisih Pretest dan Posttest kelas eksperimen 2 yang menggunakan model Discovery Learning dengan kelompok kontrol yaitu 0,27 dan 0,96. 
Tabel 8. Test of Normality

Tabel 7. Selissih Pretes dan Postes Eks 1 dan 2

\begin{tabular}{||l|l|l|l||}
\hline $\begin{array}{c}\text { Penguku } \\
\text { ran }\end{array}$ & \multicolumn{2}{|c|}{ Rata-rata (Mean) } & Selisih \\
\hline & $\begin{array}{c}\text { Eksperime } \\
\text { n 1 }\end{array}$ & $\begin{array}{c}\text { Eksperime } \\
\text { n 2 }\end{array}$ & \\
\hline Pretest & 60,36 & 60,92 & 0,56 \\
\hline Posttest & 75,61 & 70,43 & 5,18 \\
\hline
\end{tabular}

Selisih Pretest dan Posttest kelas eksperimen 1 dan eksperimen 2 yang menggunakan model Problem Solving dan Discovery Learning dengan kelompok kontrol yaitu 0,56 dan 5,18.

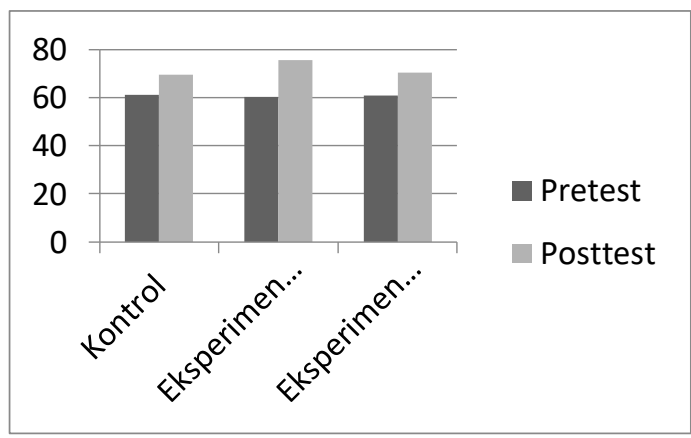

Gambar 1. Diagram kemampuan berpiki kritis

Analisis data menggunakan Deskriptif Statistics untuk menguji normalitas, dan homogenitas. Hal ini berbeda dengan analisis data uji beda $(\mathrm{t})$ yang menggunakan independent $t$ test. Untuk mengetahui perbedaan rata-rata yang menggunakan model konvensional, model Problem Solving, dan model Discovery Learninge.

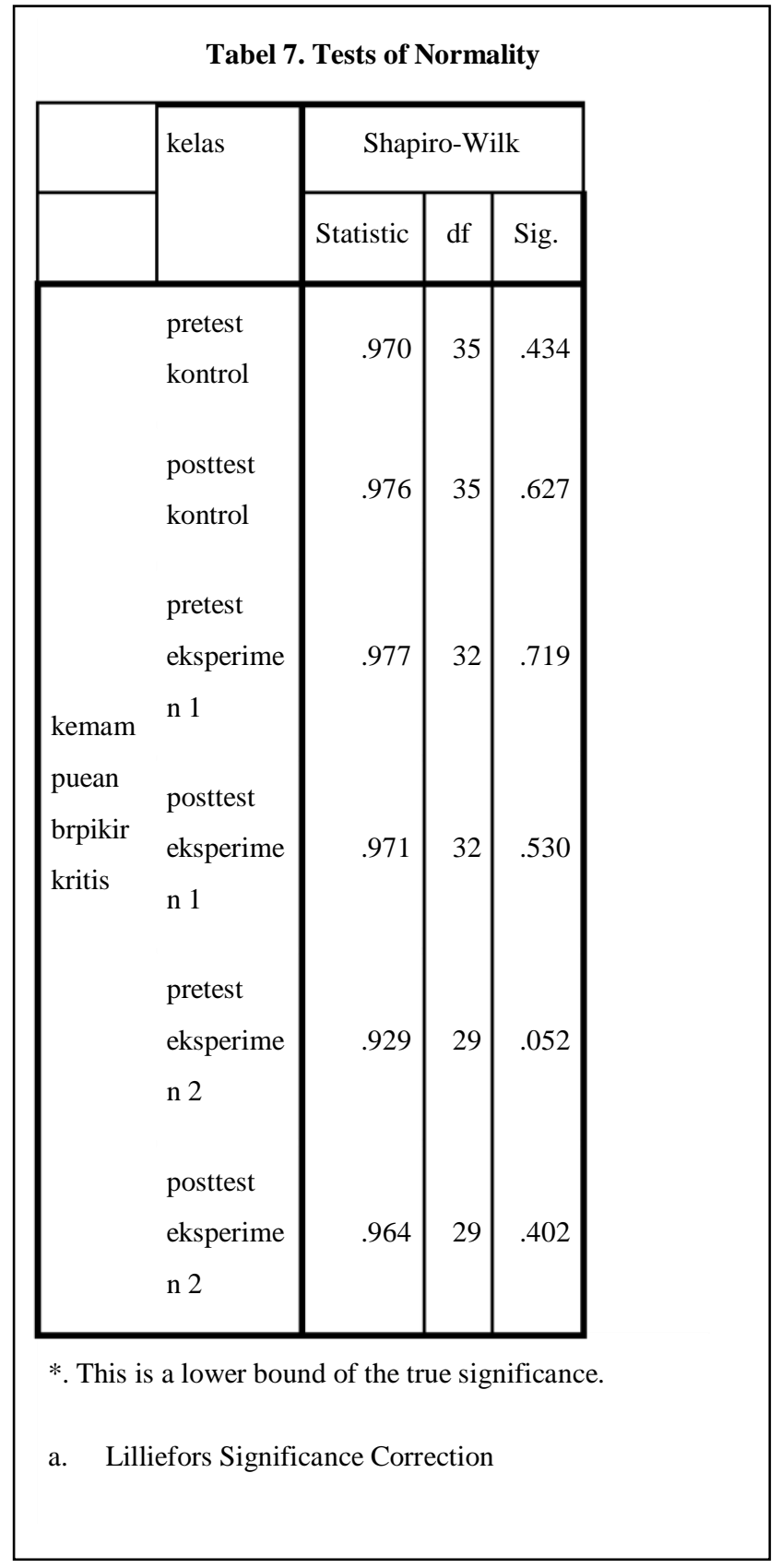

Berdasarkan nilai uji normalitas, maka dapat disimpulkan bahwa data kelompok kontrol berdistribusi normal. Hal ini dapat dilihat dari nilai sig pada pretest yaitu 434>0,05, dan nilia posttest 0,627>0,05. Pada kelompok model Problem Solving berdistribusi normla, hal ini dapat dilihat pada nilai sig pretest $719>0,05$, dan nilai posttest 530>0,05. Pada kelompok eksperimen 2 model Discovery Learning data berdistribusi normal hal ini dapat diliha dari nilai sig pretest $0,052>0,05$, dan nilai posttest $0,402>0,05$. 
367 Efektivitas Model Pembelajaran Problem Solving dan Discovery Learning Terhadap Kemampuan Berpikir Kritis Siswa Sekolah Dasar-Maulid Anwar Siddiq, Tego Prasetyo

Tabel 8. Test of Homogeneity of Variance Preteest

\begin{tabular}{||r|r|r|r|r|}
\hline & $\begin{array}{r}\text { Levene } \\
\text { Statistic }\end{array}$ & $\begin{array}{c}\text { df } \\
\text { df2 }\end{array}$ & Sig. \\
\hline $\begin{array}{l}\text { Based } \\
\text { on } \\
\text { Mean } \\
\text { Based } \\
\text { on } \\
\text { Media } \\
\text { n }\end{array}$ & 2.623 & 2 & 93 & .078 \\
kemam $\begin{array}{l}\text { Based } \\
\text { on } \\
\text { puan } \\
\text { berpiki } \\
\text { Media } \\
\text { r kritis } \\
\text { nand } \\
\text { with } \\
\text { adjuste } \\
\text { d df } \\
\text { Based } \\
\text { on } \\
\text { trimme } \\
\text { d } \\
\text { mean }\end{array}$ & 2.726 & 2 & 93 & .071 \\
& 2.718 & 2 & 93 & .071 \\
\hline
\end{tabular}

Berdasarkan tabel uji homogenitas varians Pretest di atas dapat diketahui bahwa berdasarkan rata-rata signifikan 0,078. Data dapat dikatakan homogen jika nilai signifikan lebih dari 0,05 . Berdasarkan uji homogenitas diatas dapat disimpulkan bahwa data homogen karena nilai 0,078 lebih besar dari 0,05 .
Tabel 9. Test of Homogeneity of Variance Posttest

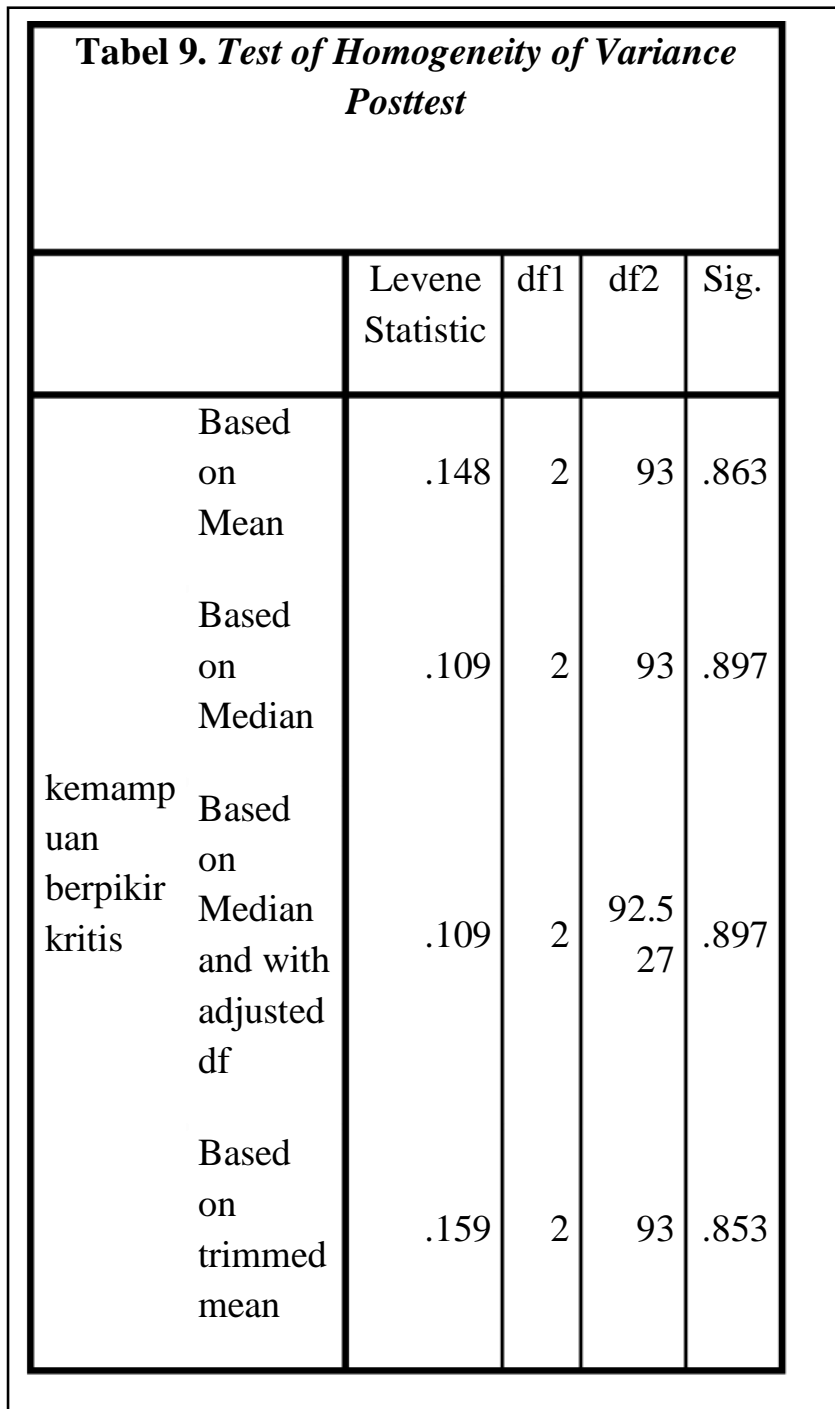

Berdasarkan tabel uji homogenitas varians Posttest di atas dapat diketahui bahwa berdasarkan rata-rata signifikan 0,863. Data dapat dikatakan homogen jika nilai signifikan lebih dari 0,05. Berdasarkan uji homogenitas diatas dapat disimpulkan bahwa data homogen, karena nilai 0,863 lebih besar dari 0,05 .

Tabel 10. Annova

\begin{tabular}{|l|r|r|r|r|r|}
\hline & $\begin{array}{r}\text { Sum } \\
\text { of } \\
\text { Squar } \\
\text { es }\end{array}$ & df & $\begin{array}{c}\text { Mean } \\
\text { Square }\end{array}$ & F & Sig. \\
\hline $\begin{array}{l}\text { Betwee } \\
n\end{array}$ & $\begin{array}{r}709.0 \\
54\end{array}$ & 2 & $\begin{array}{r}354.52 \\
\text { Groups }\end{array}$ & $\begin{array}{r}4.38 \\
6\end{array}$ & .015 \\
Within & $\begin{array}{r}7517 . \\
500\end{array}$ & 93 & 80.833 & & \\
Groups & $\begin{array}{r}826 . \\
553\end{array}$ & 95 & & & \\
Total & & & & \\
\hline
\end{tabular}


Berdasarkan tabel Annova dapat disimpulkan bahwa hasil uji Annova memperoleh nilai signifikan $0,015<0,05$, sehingga $\mathrm{H}_{0}$ ditolak, yang berarti berdapat perbedaan antara yang menggunakan kelas kontrol dan eksperimen.

\section{Tabel 11. Hasil Uji N-Gain Kelas Kontrol}

\begin{tabular}{|cccccc}
\hline No & $\begin{array}{c}\text { N- } \\
\text { Gain }\end{array}$ & Kategori & No & $\begin{array}{c}\text { N- } \\
\text { Gain }\end{array}$ & Kategori \\
\hline 1 & 0,21 & Rendah & 19 & 0.76 & Tinggi \\
\hline 2 & 0.2 & Rendah & 20 & 0.42 & Sedang \\
\hline 3 & 0.71 & Tinggi & 21 & 0.29 & Rendah \\
\hline 4 & 0.21 & Rendah & 22 & 0.22 & Rendah \\
\hline 5 & 0.17 & Rendah & 23 & 0.28 & Rendah \\
\hline 6 & 0.14 & Rendah & 24 & 0.3 & Sedang \\
\hline 7 & 0.14 & Rendah & 25 & 0.1 & Rendah \\
\hline 8 & 0.09 & Rendah & 26 & 0.12 & Rendah \\
\hline 9 & 0.15 & Rendah & 27 & 0.09 & Rendah \\
\hline 10 & 0.03 & Rendah & 28 & 0.25 & Rendah \\
\hline 11 & 0.37 & Sedang & 29 & 0.12 & Rendah \\
\hline 12 & 0.27 & Rendah & 30 & 0.05 & Rendah \\
\hline 13 & 0.27 & Rendah & 31 & 0.14 & Rendah \\
\hline 14 & 0.22 & Rendah & 32 & 0.11 & Rendah \\
\hline 15 & 0,15 & Rendah & 33 & 0.1 & Rendah \\
\hline 16 & 0,14 & Rendah & 34 & 0.11 & Rendah \\
\hline 17 & 0,15 & Rendah & 35 & 0.13 & Rendah \\
\hline 18 & 0,02 & Rendah & & & \\
\hline & & & & & \\
\hline & & & & & \\
\hline 1
\end{tabular}

Berdasarkan tabel Hasil Uji N-Gain Kelas Kontrol, maka presentasi nilai tinggi $6 \%$, sedang $9 \%$, dan rendah $85 \%$.
Tabel 12. Hasil Uji N-Gain Kelas PS

\begin{tabular}{|cccccc|}
\hline No & $\begin{array}{c}\text { N- } \\
\text { Gain }\end{array}$ & Kategori & No & $\begin{array}{c}\text { N- } \\
\text { Gain }\end{array}$ & Kategori \\
\hline 1 & 0,49 & Sedang & 17 & 0,23 & Rendah \\
\hline 2 & 0,26 & Rendah & 18 & 0,14 & Rendah \\
\hline 3 & 0,79 & Tinggi & 19 & 0,66 & Sedang \\
\hline 4 & 0,35 & Sedang & 20 & 0,21 & Rendah \\
\hline 5 & 0,35 & Sedang & 21 & 0,45 & Sedang \\
\hline 6 & 0,28 & Rendah & 22 & 0,6 & Sedang \\
\hline 7 & 0,22 & Rendah & 23 & 0,34 & Sedang \\
\hline 8 & 0,51 & Sedang & 24 & 0,55 & Sedang \\
\hline 9 & 0,38 & Sedang & 25 & 0,17 & Rendah \\
\hline 10 & 0,48 & Sedang & 26 & 0,46 & Sedang \\
\hline 11 & 0,72 & Tinggi & 27 & 0,18 & Rendah \\
\hline 12 & 0,44 & Sedang & 28 & 0,49 & Sedang \\
\hline 13 & 0,45 & Sedang & 29 & 0,23 & Rendah \\
\hline 14 & 0,49 & Sedang & 30 & 0,49 & Sedang \\
\hline 15 & 0,46 & Sedang & 31 & 0,51 & Sedang \\
\hline 16 & 0,23 & Rendah & 32 & 0,28 & Rendah \\
\hline & & & & & \\
\hline
\end{tabular}

Tabel 13. Hasil Uji N-Gain Kelas DS

\begin{tabular}{|c|c|c|c|c|c|}
\hline No & $\begin{array}{c}\mathrm{N}- \\
\text { Gain }\end{array}$ & Kategori & No & $\begin{array}{c}\mathrm{N}- \\
\text { Gain }\end{array}$ & Kategori \\
\hline 1 & 0,2 & Rendah & 16 & 0,52 & Sedang \\
\hline 2 & 0,21 & Rendah & 17 & 0,47 & Sedang \\
\hline 3 & 0,65 & Sedang & 18 & 0,45 & Sedang \\
\hline 4 & 0,12 & Rendah & 19 & 0,52 & Sedang \\
\hline 5 & 0,2 & Rendah & 20 & 0,17 & Rendah \\
\hline 6 & 0,33 & Sedang & 21 & 0,75 & Tinggi \\
\hline 7 & 0,11 & Rendah & 22 & 0,49 & Sedang \\
\hline 8 & 0,21 & Rendah & 23 & 0,27 & Rendah \\
\hline 9 & 0,31 & Sedang & 24 & 0,19 & Rendah \\
\hline 10 & 0,01 & Rendah & 25 & 0,07 & Rendah \\
\hline 11 & 0,52 & Sedang & 26 & 0,07 & Rendah \\
\hline 12 & 0,36 & Sedang & 27 & 0,52 & Sedang \\
\hline 13 & 0,35 & Sedang & 28 & 0,47 & Sedang \\
\hline 14 & 0,32 & Sedang & 29 & 0,17 & Rendah \\
\hline 15 & 0,45 & Sedang & & & \\
\hline
\end{tabular}

Berdasarkan tabel Hasil Uji N-Gain Kelas Problem Solving, maka presentasi nilai tinggi $3 \%$, sedang $52 \%$, dan rendah $45 \%$. 
Tabel 14. Rata-rata uji N-Gain

\begin{tabular}{|l|l|l|}
\hline No & Kelompok & Rata-rata \\
\hline 1. & Kontrol & 0,20 \\
\hline 2 & Eksperimen 1 & 0,40 \\
\hline 3 & Eksperimen 2 & 0,33 \\
\hline
\end{tabular}

Berdasarkan Hasil Uji N-Gain pada kelompok kontrol yang menggunakan pembelajaran konvensional mengalami peningkatan sebesar 0,20 yang berarti rata-rata kelompok kontrol rendah. Hasil Uji N-gain kelompok eksperimen 1 dengan perlakuan menggunakan model Problem Solving mengalami peningkatan 0,40 yang berarti rata-rata kelompok eksperimen 1 mengalami peningkatan kategori sedang. Hasil Uji N-Gain pada kelompok eksperimen 2 yang menggunakan model Discovery Learning mengalami peningkatan sebesar 0,33 yang berarti rata-rata kelompok eksperimen 2 mengalami peningkatan sedang. Dapat disimpulkan bahwa kelompok eksperimen dan kontrol yang mengalami peningkatan lebih tinggi yaitu eksperimen 1 yang menggunakan model Problem Solving.

\section{SIMPULAN}

Penelitian menggunakan jenis penelitian eksperimen semu. Desain penelitian menggunakan Nonequivalent Control Group Design. Penelitian ini bertujuan untuk mengetahui efektifitas model Problem solving, dan Discovery Learning terhadap kemampuan berpikir kritis siswa kelas 5 SD dalam pelajaran Matematika. Teknik pengumpulan dalam penelitian ini berupa observasi dan tes. Observasi didapatkan dengan presentase keterlaksanaan data berupa tahapan- tahapan implementasi model pembelajaran, sedangkan teknik tes berupa tes awal (Pretest) dan tes akhir (Posttest) dalam bentuk tes uraian. Teknik analisis data berupa Deskriptif kuantitatif yang digunakan untuk uji prasyarat, dan Uji Annova, agar dapat mengetahui perbedaan ratarata antara yang menggunakan model kontrol, Problem Solving, dan Discovery Learning. Hasil uji Annova memperoleh nilai signifikan $0,015<0,05$, sehingga $\mathrm{H}_{0}$ ditolak, yang berarti berdapat perbedaan antara yang menggunakan model kontrol dan eksperimen. Hal ini dapat dilihat dari hasil rata-rata pretest dan posttest pembelajaran konvensional 61,19 dan 69,47. Ratarata nila pretest dan posttest pada kelompok eksperimen yang menggunakan model Problem Solving yaitu 60,36 dan Posttest 75,6, dan nilai rata-rata postest model Discovery Leraning yaitu 60,92 dan Posttest 70,43. Hal ini dapat diambil kesimpulan bahwa model Problem Solving lebih efektif dibandingkan dengan model Discovery Learning.

\section{DAFTAR PUSTAKA}

Arifin, Z. (2012). Penelitian Pendidikan: Metode dan Paradigma Baru. Bandung:

Remaja Rosdakarya.

Darmadi. (2017). Pengembangan Model dan Metode Pembelajaran dalam Dinamika Belajar Siswa. In Deepublish.

Frisca Meidinda, E. A., \& Jusra, H. (2018). Pengaruh Model Pembelajaran Discovery Learning Terhadap Kemampuan Berpikir Kritis Matematis Siswa Kelas Viii. Seminar Nasional Pendidikan Matematika 2018, I.

Kurniaman, O., Noviana, E., \& Dasar, S. (2013). Sikap dan Pengetahuan Otang Kurniaman, Eddy Noviana Jurnal Primary Program Studi Pendidikan Guru Sekolah Dasar Fakultas Keguruan dan Ilmu Pendidikan. Universitas Riau.

Maarif, H., \& Wahyudi, W. (2015). 
370 Efektivitas Model Pembelajaran Problem Solving dan Discovery Learning Terhadap Kemampuan Berpikir Kritis Siswa Sekolah Dasar-Maulid Anwar Siddiq, Tego Prasetyo

Eksperimentasi Problem Based Learning Dan Circ Dalam Menyelesaikan Soal Cerita Matematika Siswa Kelas 5 Sd. Scholaria: Jurnal Pendidikan Dan Kebudayaan. https://doi.org/10.24246/j.scholaria.2015.v5.i 2.p97-115

Permendikbud No.22 Tahun 2016 Tentang Standar Proses Pendidikan Dasar dan Menengah

Permendikbud No 69 Tahun 2013 Tentang Kerangka Dasar dan Struktur Kurikulum Sekolah Menengah Atas/Madrasah Aliyah

Primandari, P. A., Sulasmono, B. S., \& Setyaningtyas, E. W. (2019). Perbedaan Pengaruh Model Kooperatif Tipe Tgt Dan Stad Dengan Multimedia Interaktif Ceria Terhadap Sikap Sosial Dan Hasil Belajar Kognitif Pada Pembelajaran Tematik Kelas 5 SD. Jurnal Basicedu. https://doi.org/10.31004/basicedu.v3i1.85

Rusman. (2012). Model-model Pembelajaran Mengembangkan Profesionalisme Guru. In Jakarta: Rajawali Pers.

Oktaviani, W., Kristin, F., \& Anugraheni, I. (2018). Penerapan Model Pembelajaran Discovery Learning Untuk Meningkatkan Kemampuan Berpikir Kritis Dan Hasil Belajar Matematika Siswa Kelas 5 SD. Jurnal Basicedu. https://doi.org/10.31004/basicedu.v2i2.41

Sisnanto, S. (2019). Efektivitas Model Pembelajaran Problem Solving Dan Group Investigationterhadap Peningkatan Kemampuan Berpikir Kritis Siswa Kelas 4 SD Dalam Pelajaran Matematika. Jurnal Pajar (Pendidikan Dan Pengajaran). https://doi.org/10.33578/pjr.v3i4.7538

Sugiyono. (2012). Metode Penelitian Kuantitatif, Kualitatif dan R \& D.Bandung:Alfabeta. Metode Penelitian Kuantitatif, Kualitatif Dan $\begin{array}{lll}R & \& & \text { D.Bandung:Alfabeta. }\end{array}$ https://doi.org/10.1017/CBO9781107415324. 004

Sumianto, S. (2018). Penerapan Pendekatan Matematika Realistik (Pmr) Untuk Meningkatkan Hasil Belajar Matematika Siswa Kelas V Al-Azim Sdit Raudhatur
Rahmah Pekanbaru. Jurnal Basicedu. https://doi.org/10.31004/basicedu.v2i1.26

Suyanto, \& Jihad, A. (2013). MENJADI GURU PROFESIONAL: Strategi Meningkatkan Kualifikasi dan Kualitas Guru di Era Global. In Penerbit Erlangga.

Yaumi, M. (2012). Pembelajaran Berbasis Multiple Intelligences. Jakarta: PT Dian Rakyat. 